\title{
Defensive behaviors of the Oriental armyworm Mythimna separata in response to different parasitoid species (Hymenoptera: Braconidae)
}

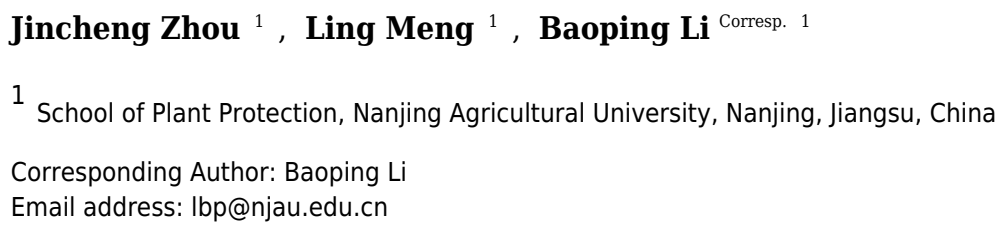

This study examined defensive behaviors of Mythimna separata (Lepidoptera: Noctuidae) larvae varying in body size in response to two parasitoids varying in oviposition behavior; Microplitis mediator females sting the host with the ovipositor after climbing onto it while Meteorus pulchricornis females make the sting by standing at a close distance from the host. Mythimna separata larvae exhibited evasive (escaping and dropping) and aggressive (thrashing) behaviors to defend themselves against parasitoids $M$. mediator and $M$. pulchricornis. Escaping and dropping did not change in probability with host body size or parasitoid species. Thrashing did not vary in frequency with host body size, yet performed more frequently in response to $M$. mediator than to M. pulchricornis. Parasitoid handling time and stinging likelihood varied depending not only on host body size but also on parasitoid species. Parasitoid handling time increased with host thrashing frequency, similar in slope for both parasitoids yet on a higher intercept for $M$. mediator than for $M$. pulchricornis. Handling time decreased with host size for $M$. pulchricornis but not for $M$. mediator. The likelihood of realizing an ovipositor sting decreased with thrashing frequency of both small and large hosts for M. pulchricornis, while this was true only for large hosts for $M$. mediator. Our results suggest that thrashing behavior of $M$. separata larvae has a defensive effect on parasitism, depending on host body size and parasitoid species with different oviposition behaviors. 
1 Defensive behaviors of the Oriental armyworm Mythimna separata in response to different

2

3

4

5

6

7

8

9

10

11

12

13

14

15

16

17

18

19

20

21 parasitoid species (Hymenoptera: Braconidae)

Jincheng Zhou, Ling Meng, Baoping Li*

(School of Plant Protection, Nanjing Agricultural University, No. 1 Weigang Rd, Nanjing,

Jiangsu 210095, P. R. China)

* Corresponding author: Baoping Li

School of Plant Protection

Nanjing Agricultural University

Weigang 1\#, Nanjing, Jiangsu Province, Zip code: 210095

E-mil: 1bp@njau.edu.cn 
Defensive behaviors of the Oriental armyworm Mythimna separata in response to different

\section{parasitoid species (Hymenoptera: Braconidae)}

\section{Abstract:}

This study examined defensive behaviors of Mythimna separata (Lepidoptera: Noctuidae) larvae varying in

body size in response to two parasitoids varying in oviposition behavior; Microplitis mediator females sting

the host with the ovipositor after climbing onto it while Meteorus pulchricornis females sting by standing at a

close distance from the host. Mythimna separata larvae, whether small or large in body size, exhibited

escaping and dropping behaviors in the same probability to defend against both parasitoid species, but

performed thrashing behavior more frequently against $M$. mediator than against $M$. pulchricornis. The efficacy

of defensive behaviors varied depending on host body size and parasitoid species. The likelihood of stinging

decreased with thrashing frequency of both small and large hosts for M. pulchricornis, while this was true only

for large hosts for M. mediator. While host-handling time increased with host thrashing frequency at the same rate for both parasitoid species, it was overall shorter for M. mediator than for M. pulchricornis. In addition, host-handling time decreased with host body size for M. pulchricornis but did not change with it for $M$. mediator. Our results suggest that thrashing behavior of $M$. separata larvae has a defensive effect on parasitism, depending on host body size and parasitoid species with different oviposition behaviors. 


\section{Introduction}

44 Since successful parasitism by parasitoids results in the death of the host, natural selection should favor

the evolution of host defenses against parasitoids. Herbivore insects perform a wide variety of defense

mechanisms in response to their parasitoids, including morphological, chemical, physiological, and behavioral

traits (Gross, 1993; Godfray, 1994). Behavioral defenses are observed in a number of herbivorous insect

groups, conferring protection against attacking parasitoids (Gross, 1993). For example, lepidopteran larvae

perform a wide array of behavioral defenses in response to parasitoids, and these defenses fall into three broad

categories: evasive, aggressive, and associative behaviors (Gentry \& Dyer, 2002; Greeney, Dyer \& Smilanich,

2012). Yet, these categories of defensive behaviors include many variations, combinations, and modifications

of innumerable potential life history strategies and behaviors, and their expression or employment may vary

ontogenetically, temporarily, or in response to different enemies (Stamp, 1982; Cornell, Stamp \& Bowers,

1987; Allen, 1990; Greeney, Dyer \& Smilanich, 2012). Many studies have shown that host larval resistance to

attacking parasitoids increases with age (and therefore body size) (Gross, 1993; Firlej, Lucas, Coderre \&

Boivin, 2010; Kageyama \& Sugiura, 2016). Such resistance can be achieved by a combination of morphology

(e.g. increasingly tough exoskeleton) and behaviors associated with host age (or size) ( Brodeur, Geervliet \&

Vet, 1998; Yazdani, Glatz \& Keller, 2015; Ameri, Rasekh \& Michaud, 2014; Kageyama \& Sugiura, 2016).

These defensive mechanisms often increase host handling time, shape parasitoid host-preference ( Lucas et al.,

1997; Potting, Vermeulen \& Conlong, 1999) and likely decrease parasitism success by parasitoids (Gross,

1993).

Individual herbivorous insect species are often attacked by more than one species of parasitoids (Hawkins,

1984), which is referred to as parasitoid species loads (Godfray, 1994). If a host species is parasitized by 
different parasitoid species that use different attacking tactics, selection can favor variation in host defenses that encode this information. According to this theory, we hypothesize that a larval host should behave differently in defense against different parasitoid species that have dissimilar oviposition behaviors. We tested this hypothesis using the oriental armyworm, Mythimna separata (Walker) as the host attacked by two larval parasitoid species, Microplitis mediator (Haliday) and Meteorus pulchricornis (Wesmael). The host larvae exhibit active behaviors in defense against parasitoids (Lauro et al., 2005; Chu et al., 2014). Its two parasitoid species differ in approaching the host: $M$. mediator females climb on the host to sting it with their ovipositors (Wang et al., 1984; Arthur \& Mason, 1986), while M. pulchricornis females stand at a close distance from the host to make the stinging (Yamamoto, Chau \& Maeto, 2009).

The host M. separata is a polyphagous pest of grain crops, causing major losses in crop production annually in China and other Asian countries (Sharma, Sullivan \& Bhatnagar, 2002; Jiang et al., 2014). Each year it migrates by a seasonal, multi-generation, long-distance roundtrip between southern and northern China (Jiang et al., 2011). Microplitis mediator is known to attack the host species in the family Noctuidae and Geometridae (Lepidoptera). It was one of the dominant parasitoids of M. separata lavae in China (Wang et al., 1984; Arthur \& Mason, 1986; He, 2004;Li et al., 2006). Meterous pulchricornis is a generalist parasitoid that is known to attack hosts in at least 12 families of the Lepidoptera (Maeto, 1990; Harvey, Sano \& Tanaka, 2010; Malcicka \& Harvey, 2014; Xu et al., 2016). Both parasitoid species have a similar preference for host stages (Foerster \& Doetzer, 2003; Lauro et al., 2005; Li et al., 2006; Liu and Li, 2006). M. pulchricornis is approximately twice the size of M. mediator (Malcicka \& Harvey, 2014). Both parasitoids are important biological control agents of various noctuid pests and have been introduced widely to control both natural and novel hosts (e.g. Arthur and Mason, 1986; Fuester et al., 1993; Berry, 1997; Beery \& Walker, 2004; Li et al., 
2006b; Liu \& Li, 2006; Chhagan et al., 2008; Li et al., 2010).

To test our hypothesis, we first determined how defensive behaviors of M. separata larvae varied with their own body size or two parasitoid species, and then examined how host defensive behavior and body size influenced the likelihood of stinging and handling time of the two parasitoids. The understanding of effectiveness of behavioral defenses sheds light on the evolution of host-parasitoid behavioral interactions, and helps to explain why this host species is more often parasitized by one parasitoid than by the other.

\section{Insects preparations}

\section{Materials and Methods}

Oriental armyworms, M. separata, were provided by the Research Institute of Agriculture and Forestry of Hebei province, China, in 2013 and since then has been maintained in the insectary. Larvae were reared on semi-artificial diets $(\mathrm{Bi}, 1989)$. They were reared in groups of 40-60 from neonates in glass jars $(9 \mathrm{~cm}$ height and $20 \mathrm{~cm}$ diameter). Pupae were collected in a plastic box $(5 \mathrm{~cm}$ height and $8 \mathrm{~cm}$ diameter) for adult emergence. Adults in a group of 40-50 were placed in a rectangular cage, where a $10 \%$ honey solution was provided as food via a large cotton ball and pieces of nylon rope were suspended from the cage roof as substrates for egg deposition. Eggs were collected in a petri-dish with a soft brush and maintained for larval hatching. The $2^{\text {nd }}$ or $3^{\text {rd }}$ instar larvae, weighted from 1.5 to $50 \mathrm{mg}$, were used as hosts in the experiment.

The parasitoid M. mediator was provided by the Research Institute of Agriculture and Forestry of Hebei province, China, in 2013 and since then has been maintained with M. separata $2^{\text {nd }}$ or $3^{\text {rd }}$ instar larvae as hosts 
106 in the insectary. Host larvae in groups were placed in a plastic box and then two female wasps were released.

107 After 24 hours the wasps were removed and the larvae were reared on the semi-artificial diets until offspring

parasitoid larvae egressed from host larvae and pupated. Parasitoid pupae were collected in groups in a glass tube ( $8 \mathrm{~cm}$ height $\times 2 \mathrm{~cm}$ diameter) to allow adults to emerge. Emerged wasps were maintained in groups in a vial to allow mating for two days, during which time a $10 \%$ honey solution was provided as supplementary food via a piece of cotton thread. Four days old, naive female wasps were used in the experiment.

The parasitoid M. pulchricornis is thelytokous and its laboratory stock was established from rearing the tobacco cutworm Spodoptera litura larvae collected from soybean fields in the northern suburb of Nanjing in 2013. Thereafter it has been maintained using M. separata larvae as hosts. The $2^{\text {nd }}$ or $3^{\text {rd }}$ instar larvae were exposed in groups to parasitism in vials. The parasitoid pupae were collected in vials to allow adults to emerge.

The emerged wasps were kept in glass tubes and provided with a $10 \%$ honey solution via a piece of cotton thread. Four to six days old, naive adults were used in the experiment.

\section{Experimental protocol}

Host and parasitoid behaviors were observed on potted wheat seedlings in a transparent cage $(12 \mathrm{~cm}$ height and $4.5 \mathrm{~cm}$ diameter, the top being covered by nylon gauze). Triticum aestivum $\mathrm{L}$ wheat seeds were planted in pots $(9 \mathrm{~cm}$ height and $6 \mathrm{~cm}$ in diameter) with peat moss-sand and soil. Wheat seedlings grown to a height of 10 $\mathrm{cm}$ with 7 leaves were used as food plants for host larvae. A larva was placed on potted wheat seedlings after being weighed (Mettler Toledo AL204-IC Electronic Microbalance, accurate to $0.0001 \mathrm{~g}$ ), and an hour later a female wasp was released into the cage. The host and wasp were observed continuously for a maximum of 30 min, during which time the frequency of behaviors exhibited by the host and wasp (Table 1) were noted. The 
observation was terminated before $30 \mathrm{~min}$ if either the wasp made a successful sting of the host with its ovipositor, or the host fell off the plant or escaped before a ovipositor sting was made. Each parasitoid female was tested once. A total of 86 females (replicates) for each parasitoid species were observed.

\section{Statistical analyses}

We first analyzed host defensive behaviors as a function of host body weight and parasitoid species, by applying a logistic model $($ link $=$ logit $)$ to estimate the probability of host dropping and escaping, and by a simple linear model to estimate frequency of host thrashing (weighted by observation time). We then used a logistic model to estimate the probability of ovipositor stinging, and a generalized linear model with gamma distribution to evaluate host handling time, which is conveniently described by gamma distribution (Kohlmann, Matis \& Risenhoover, 1999), Host thrashing, host body size, and parasitoid species were tested as predictor variables. Overdispersion was taken into account where appropriate via empirical estimation of scaling parameters (Faraway, 2016). We did not consider host dropping and escaping behaviors in estimating parasitoid handling time and stinging because the behavioral observation was designed to be terminated when the host dropped from the plant or escaped. Robust standard errors were used to control for the violation of the distribution assumption for the parameter estimation (Croux, Dhaene \& Hoorelbeke, 2004). Analyses were carried out with R ver. 3.3.1 (R Development Core Team, 2012).

\section{Results}

The probability of host escaping was not significantly influenced by host body weight $\left(\chi^{2}=3.37, P=\right.$ $0.06)$, wasp species $\left(\chi^{2}=1.59, P=0.21\right)$, or their interaction $\left(\chi^{2}=1.33, P=0.25\right)$. The proportion of hosts 
148

149

150

151

152

153

154

155

156

157

158

159

160

161

162

163

164

165

166

167

168

escapeding was $31.4 \%$ (standard deviation, $\mathrm{SD}=46.7 \%, n=86$ ) in response to $M$. mediator (Fig. $1 \mathrm{~A}$ ) and $40.7 \%$

$(\mathrm{SD}=49.2 \%, n=86)$ to M. pulchricornis (Fig. 1B).

The probability of host dropping was not significantly influenced by host weight $\left(\chi^{2}=2.80, P=0.09\right)$,

wasp species $\left(\chi^{2}=0.36, P=0.55\right)$, or their interaction $\left(\chi^{2}=0.38, P=0.54\right)$. The proportion of hosts

droppeding was $18.6 \%(\mathrm{SD}=39.1 \%, n=86)$ in response to $M$. mediator (Fig. $2 \mathrm{~A})$ and $22.1 \%(\mathrm{SD}=41.7 \%, n$

= 86) to M. pulchricornis (Fig. 2B).

Host thrashing frequency was not significantly affected by the interaction between host body weight and wasp species $\left(F_{1,166}=1.74, P=0.19\right)$, or host weight $\left(F_{1,166}=1.95, P=0.16\right)$, but it was influenced by wasp species $\left(F_{1,166}=5.59, P<0.05\right)$. Thrashing frequency was nearly 10 times higher in response to $M$. mediator (on average 21.11 times/10min) than in response to M. pulchricornis (on average 2.23 times/10min) (Fig. 3).

The probability of the stinging by parasitoids was affected by a 3-way interaction among host body weight, thrashing frequency and parasitoid species $\left(\chi^{2}=4.11, P<0.05\right)$. For $M$. mediator, it decreased with thrashing frequency when the host was larger but increased with it when the host was smaller (Fig. 4A). For $M$. pulchricornis, however, it decreased with thrashing frequency regardless of host body weight (Fig. 4B).

Host-handling time was influenced by a 2-way interaction between host body weight and parasitoid species $\left(\chi^{2}=7.17, P<0.01\right)$. It decreased with host body weight for M. pulchricornis, but not for M. mediator (Fig 5A). It increased with host thrashing frequency in both parasitoid species $\left(\chi^{2}=13.81, P<0.001\right.$; Fig. 5B), yet was overall shorter by $36 \%$ for M. mediator than for M. pulchricornis (Fig. 5B).

\section{Discussion}


different species of parasitoids that differ in oviposition behaviors. We showed that the larvae, whether small or large in size, thrashed the head more frequently in response to M. mediator than to M. pulchricornis, though they dropped and escaped in the same likelihood in response to them. As a result of such thrashing defenses, $M$. mediator spent shorter time to handle the host than did M. pulchricornis. Furthermore, M. mediator females increased the likelihood of stinging when smaller larvae thrashed more frequently, while M. pulchricornis females decrease it when confronting such larvae.

The different oviposition behaviors between these two parasitoid species can explain the variable behavioral responses of $M$. separata larvae to them and the consequences of these defenses on them. Microplitis mediator females have to climb onto the host body to insert the ovipositor into the host (Wang et al., 1984; Arthur \& Mason, 1986), probably owing to its shorter ovipositor (He, 2004). Meterous pulchricornis females, however, with a longer ovipositor, furtively approach the host and make an attack while maintaining a distance from it (Yamamoto, Chau \& Maeto, 2009). It is expected that climbing onto the host body by $M$. mediator females would incur more frequent thrashing than maintaining a distance from the host by $M$. pulchricornis females. However, M. mediator females spent shorter time to handle the host than did $M$. pulchricornis females, which suggests that the host defensive behavior is more effective against $M$. pulchricornis than against M. mediator. Smaller or younger hosts are often less defensive than larger or older hosts, owing mainly to stronger thrashing behaviors or tough exoskeleton in larger or older hosts (Brodeur, Geervliet \& Vet, 1998; Firlej, Lucas, Coderre \& Boivin, 2010; Ameri, Rasekh \& Michaud, 2014; Yazdani, Glatz \& Keller, 2015; Kageyama \& Sugiura, 2016). Thrashing can be a powerful counterattack to avoid contact with ovipositors, and may even result in dislodging or injuring parasitoids in some larvae (Myers \& Smith, 1978; Stamp, 1982; Heinz \& Parella, 1989). On the other hand, remaining motionless can also be an 
190

191

192

effective defense against parasitoids (Richerson \& DeLoach, 1972; Rotheray, 1981), for in some parasitoid species visual cues from moving larvae are necessary for a successful oviposition (Nakamatsu \& Tanaka, 2005; Yamamoto, Chau \& Maeto, 2009). Our observation that M. pulchricornis spent longer host-handling time and had an overall lower likelihood of stinging than did $M$. mediator The suggestion that $M$. separata is more effective to defense against attacks by $M$. pulchricornis than by $M$. mediator may partly explain why $M$. separata is less often parasitized by M. pulchricornis (Jiang et al., 2011) than by M. mediator (Li et al., 2006b; Luo et al., 2013).

Our results suggest that M. separata larvae do not adjust dropping and escaping behaviors in response to different parasitoid species, though escaping is more often exhibited than dropping. Dropping off the plant can be an effective defense against parasitoids for lepidopteran larvae (Greeney, Dyer \& Smilanich, 2012) and occurs in many other insect taxa as well (Gross, 1993), probably because it removes the host and its associated chemical and sensory cues from the immediate vicinity of the parasitoid, making it difficult to relocate. However, dropping to the ground can be costly for phytophagous insects, as it reduces feeding time and increases mortality risk (Greeney, Dyer \& Smilanich, 2012; Gish \& Inbar, 2006). Larvae that have dropped to the ground often face predation from ground predators, such as ants, spiders and carabids (Winder,1990; Lövei \& Sunderland, 1996; López \& Potter, 2000). As an alternative to dropping, another evasive behavior, escaping, was observed in M. separata larvae, whereby the caterpillar swiftly moved away on the leaf once touched by an approaching parasitoid. By escaping, host larvae can avert the first attack by parasitoids, which often give up further attack (Gross, 1993). Many studies have shown that the propensity to escape or drop shifts during larval development, being higher in earlier (therefore, smaller in body size) than later (larger) instar hosts (Stamp, 1982; Cornell, Stamp \& Bowers, 1987; Allen, 1990; Lucas, Coderre \& Brodeur, 1996). We assume 
211 that the host stages ( $2^{\text {nd }}$ and $3^{\text {rd }}$ instar) we tested were not wide enough to show the effect.

212 In total, our findings have several broad implications. First, M. separata larvae can adjust their thrashing

213 behaviors in response to different parasitoid species that have dissimilar oviposition behaviors. Second, the

214 defensive behaviors of the host are more effective against $M$. pulchricornis than against M. mediator, which

215 may help to explain the difference between the two parasitoid species in importance as biological control

216 agents of M. separata.

217

218

219

220

221

222

223

224

225 Acknowledgement:

226 We would like to thank Li Jiancheng for providing the host and its parasitoid M. mediator, and John Lazarus

for his suggestions of improving the language.

References:

231 Allen GR. 1990. Influence of host behavior and host size on the success of oviposition of Cotesia urabae and 
Dolichogenidea eucalypti (Hymenoptera: Braconidae). Journal of Insect Behavior 3: 733-749 DOI:

$$
\text { 10.1007/BF01065962 }
$$

Ameri M, Rasekh A, Michaud JP. 2014. Body size affects host defensive behavior and progeny fitness in a parasitoid wasp, Lysiphlebus fabarum. Entomologia Experimentalis Et Applicata 150:, 259-268 DOI: 10.1111/eea. 12158

Arther AP, Mason PG. 1986. Life history and immature stages of the parasitoid Microplitis mediator (Hymenoptera:Braconidae), reared on the bertha armyworm Mamestra configurata (Lepidoptera: Noctuidae). The Canadian Entomologist 118: 487-491

Brodeur J, Geervliet JBF, Vet LEM. 1998. The role of host species, age and defensive behaviour on ovipositional decisions in a solitary specialist and gregarious generalist parasitoid (Cotesia species). Entomologia Experimentalis Et Applicata 81: 125-132.DOI: 10.1007/BF00192137

Bi FC. 1989. Susceptibility to insecticides of the armyworm Mythimna separata walker reared on the artificial diet. Acta Entomologica Sinica 32:39-43

Berry JA. 1997. Meteorus pulchricornis (Wesmael) (Hymenoptera: Braconidae: Euphorinae): a new record for New Zealand. New Zealand Entomologist 20: 45-48. DOI: 10.1080/00779962.1997.9722668

Berry JA, Walker GP. 2004. Meteorus pulchricornis (Wesmael) (Hymenoptera: Braconidae: Euphorinae): an exotic polyphagous parasitoid in New Zealand. New Zealand Journal of Zoology 31: 33-44. DOI: $10.1080 / 03014223.2004 .9518357$

Chu Y, Michaud JP, Zhang J, Li Z, Wang Y, Chen H, Li J, Lu Z, Zhang Q, Liu X. 2014. Performance of Microplitis tuberculifer (Hymenoptera: Braconidae) parasitizing Mythimna separata (Lepidoptera: Noctuidae) in different larval instars. Biological Control 69: 18-23 DOI: 
253

254

255

256

257

258

259

260

261

262

263

264

265

266

267

268

269

270

271

272

273

10.1016/j.biocontrol.2013.10.014

Chhagan A, Stephens AEA, Charles JG. 2008. Developmental biology of Meteorus pulchricornis parasitizing painted apple moth. New Zealand Plant Protection 61: 12-16.

Cornell JC, Stamp NE, Bowers MD. 1987. Developmental change in aggregation, defense and escape behavior of buckmoth caterpillars, Hemileuca lucina, (Saturniidae).Behavioral Ecology \& Sociobiology 20: 383-388 DOI: 10.1007/BF00302980

Croux C, Dhaene G, Hoorelbeke D. 2004. Robust standard errors for robust estimators. Center for Economic Studies - Discussion papers:1-20 DOI: 10.1.1.487.2107

Faraway IJ. 2016. Extending the Linear Model with R. Second edition. USA(FL): CRC Press.

Firlej A, Lucas É, Coderre D, Boivin G. 2010. Impact of host behavioral defenses on parasitization efficacy of a larval and adult parasitoid. BioControl 55: 349-349 DOI: 10.1007/s10526-009-9262-5

Foerster LA., Doetzer AK. 2003. Biology of Microplitis mediator Haliday (Hymenoptera: Braconidae) parasitizing the wheat armyworm Mythimna (Pseudaletia) sequax Franclemont (Lepidoptera: Noctuidae). Neotropical Entomology 32: 81-84 DOI: 10.1590/S1519-566X2003000100011

Fuester RW, Taylor PB, Peng H, Swan K. 1993. Laboratory biology of a uniparental strain of Meteorus pulchricornis (Hymenoptera: Braconidae), an exotic larval parasite of the gypsy moth (Lepidoptera: Lymantriidae). Annals of Entomological Society of America 86: 298-304. DOI: 10.1093/aesa/86.3.298

Gentry GL, Dyer LA. 2002. On the conditional nature of neotropical caterpillar defenses against their natural enemies. Ecology 83: 3108-3119 DOI: 10.1890/0012-9658(2002) 083 [3108:OTCNON] 2.0.CO;2

Gish M., Inbar M. 2006. Host location by apterous aphids after escape dropping from the plant. Journal of Insect Behavior 19: 143-153 DOI: 10.1007/s10905-005-9009-9 
274 Godfray HCJ. 1994. Parasitoids: behavioral and evolutionary ecology. Princeton (NJ): Princeton University $275 \quad$ Press

276

277

278

279

280

281

282

283

284

285

286

287

288

289

290

291

292

293

294

Greeney HF., Dyer LA, Smilanich AM. 2012. Feeding by lepidopteran larvae is dangerous: a review of caterpillars' chemical, physiological, morphological, and behavioral defenses against natural enemies. Invertebrate Survival Journal 9: 7-34

Gross P. 1993. Insect behavioral and morphological defenses against parasitoids. Annual review of entomology 38: 251-273 DOI:10.1146/annurev.ento.38.1.251

Harvey JA, Sano T, Tanaka T. 2010. Differential host growth regulation by the solitary endoparasitoid, Meteorus pulchricornis in two hosts of greatly differing mass. Journal of Insect Physiology 56: 11781183. DOI: $10.1016 /$ j.jinsphys.2010.03.018

Hawkins BA. 1984. Pattern and Process in Host-Parasitoid Interactions. London: Cambridge University Press.

He JH 2004. Hymenoptera insect fauna of Zhejiang. Beijing: Science Press

Heinz KM, Parrella MP. 1989. Attack behavior and host size selection by Diglyphus begini on Liriomyza trifolii in chrysanthemum. Entomologia Experimentalis Et Applicata 53: 147-156 DOI: 10.1007/BF00187996

Jiang X, Luo L, Zhang L, Sappington TW, Hu Y. 2011. Regulation of migration in Mythimna separata (Walker) in china: a review integrating environmental, physiological, hormonal, genetic, and molecular factors. Environmental Entomology 40: $516-33$ DOI: 10.1603/EN10199

Jiang YY, Li CG, Zeng J, Liu J. 2014. Population dynamics of the armyworm in china: a review of the past 60 years' research. Chinese Journal of Applied Entomology 51: 890-898 DOI: 10.7679/j.issn.2095-1353.2014.109 
295 Kageyama A, Sugiura S. 2016. Caterpillar hairs as an anti-parasitoid defence. The Science of Nature 103:86 DOI:10.1007/s00114-016-1411-y

297

298

299

300

301

302

303

304

305

306

307

308

309

310

311

312

313

314

315

Kohlmann SG, Matis JH, Risenhoover KL. 1999. Estimating handling times for herbivore diets: a statistical method using the gamma distribution. Journal of Animal Ecology 68: 638-645 DOI: 10.1046/j.13652656.1999.00303.x

Lauro N, Kuhlmann U, Mason PG, Holliday NJ. 2005. Interaction of a solitary larval endoparasitoid, Microplitis mediator, with its host, Mamestra brassicae: host acceptance and host suitability. Journal of Applied Entomology 129: 567-573 DOI: 10.1111/j.1439-0418.2005.01011.x

Li J, Coudron TA, Pan W, Liu X, Lu Z., Zhang Q. 2006. Host age preference of Microplitis mediator (Hymenoptera: Braconidae), an endoparasitoid of Mythimna separata (Lepidoptera: Noctuidae). Biological Control 39: 257-261 DOI: 10.1016/j.biocontrol.2006.09.002

Li J, Yan F, Coudron TA, Zhang Q. 2006b. Field Release of the Parasitoid Microplitis mediator (Hymenoptera: Braconidae) for Control of Helicoverpa armigera (Lepidoptera: Noctuidae) in Cotton Fields in Northwestern China's Xinjiang Province. Environmental Entomology 35: 694-699 DOI: 10.1603/0046$225 \mathrm{X}-35.3 .694$

Li J, Lu Z, Qu Z, Liu W. 2010. Research Progress of Microplitis mediator and Its Application. Journal of Hebei Agricultural Sciences 14: 4-11 DOI:10.16318/j.cnki.hbnykx.2010.08.004

Liu Y, Li B. 2006. Developmental interactions between Spodoptera exigua (Noctuidae: Lepidoptera) and its uniparental endoparasitoid, Meteorus pulchricornis (Braconidae: Hymenoptera). Biological Control 38: 264-269 DOI: 10.1016/j.biocontrol.2006.01.007 
and japanese beetle (Coleoptera: Scarabaeidae) in turfgrass. Environmental Entomology 29: 116-125 DOI:

$10.1603 / 0046-225 X-29.1 .116$

Lövei GL, Sunderland KD. 1996. Ecology and behavior of ground beetles (Coleoptera: Carabidae). Annual Review of Entomology 41: 231-256 DOI: 10.1146/annurev.en.41.010196.001311

Lucas E, Coderre D, Brodeur J. 1997. Instar-specific defense of Coleomegilla maculata lengi (Col.: Coccinellidae): influence on attack success of the intraguild predator Chrysoperla rufilabris (Neur.: Chrysopidae). BioControl 42: 3-12 DOI:10.1007/BF02769874

Luo S, Michaud JP, Li J, Zhang J, Liu X, Zhang Q. 2013. Seasonal cues mediate host behaviour modification and cocoon polymorphism in Microplitis mediator (Hymenoptera: Braconidae). European Journal of Entomology 110: 271-276 DOI:10.14411/eje.2013.040

Maeto K. 1990. Systematic studies on the tribe Meteorrini (Hymenoptera: Braconidae) from Japan. V. The pulchricornis group of the genus Meteorus. Japanese Journal of Entomology 53: 581-595

Malcicka M, Harvey JA. 2014. Trade-offs between developmental parameters of two endoparasitoids developing in different instars of the same host species. Biological Control 74: 52-58. DOI:10.1016/j.biocontrol.2014.03.014

Myers JH, Smith JNM. 1978. Head flicking by tent caterpillars: a defensive response to parasite sounds. Canadian Journal of Zoology 56: 1628-1631

Nakamatsu Y, Tanaka T. 2005. How does the ectoparasitoid wasp Euplectrus Sepamtae (Hymenoptera: Eulophidae) recognize a suitable oviposition site on the host larva Pseudaletia separata (Lepidoptera: Noctuidae)?. Applied Entomology \& Zoology 40: 185-191 DOI:10.1303/aez.2005.185

Potting RPJ, Vermeulen NE, Conlong DE. 1999. Active defence of herbivorous hosts against parasitism: 
adult parasitoid mortality risk involved in attacking a concealed stemboring host. Entomologia Experimentalis Et Applicata 91: 143-148 DOI: 10.1046/j.1570-7458.1999.00476.x

R Core Team. 2016. R: A language and environment for statistical computing. R Foundation for Statistical Computing, Vienna, Austria. URL https://www.R-project.org/.

Richerson JV, Deloach CJ. 1972. Some aspects of host selection by Perilitus coccinellae. Annals of the Entomological Society of America 65: 834-839 DOI: 10.1093/aesa/65.4.834

Rotheray GE. 1981. Host searching and oviposition behaviour of some parasitoids of aphidophagous Syrphidae. Ecological Entomology 6: 79-87 DOI: 10.1111/j.1365-2311.1981.tb00974.x

Sharma HC., Sullivan DJ, Bhatnagar VS. 2002. Population dynamics and natural mortality factors of the oriental armyworm, Mythimna separata (Lepidoptera: Noctuidae), in south-central india. Crop Protection 21: 721-732 DOI: 10.1016/S0261-2194(02)00029-7

Stamp NE. 1982. Behavioral interactions of parasitoids and baltimore checkerspot caterpillars (Euphydryas phaeton). Environmental Entomology 11: 100-104

Winder L. 1990. Predation of the cereal aphid Sitobion avenae by polyphagous predators on the ground. Ecological Entomology 15: 105-110 DOI: 10.1111/j.1365-2311.1990.tb00789.x

Wang D, Nan L, Sun X, Li X. 1984. Microplitis sp. -a larval parasitoid of earlier instar larvae of Helicoverpa armigera. Natural Enemies of Insects, 6: 211-218

Xu YH, Zhou JC, Li BP, Meng L. 2016. Survival and developmental performance of Meteorus pulchricornis in intrinsic competition with Microplitis mediator within the shared host Mythimna separata (Lepidoptera: Noctuidae). Acta Entomologica Sinica 59: 322-327 DOI: 10.16380/j.kcxb.2016.03.009

Yamamoto M, Chau NNB, Maeto K. 2009. Host movement initiates oviposition behavior of Meteorus 

44:53-59 DOI: 10.1303/aez.2009.53

Yazdani M, Glatz R, Keller MA. 2015. Searching behaviour of Dolichogenidea tasmanica in response to susceptible instars of Epiphyas postvittana. Australian Journal of Zoology 63:38-45 DOI:10.1071/ZO14093

Zhang B, Li B, Meng L. 2014. Effects of selfsuperparasitism and host age on fitness-correlated traits in the solitary endoparasitoid wasp Meteorus pulchricornis. Journal of Insect Science 14: 1-11 DOI: 
Table $\mathbf{1}$ (on next page)

Description of parasitoid and host behaviors recorded 


\begin{tabular}{|c|c|c|c|}
\hline & Behavior & Description & Measurement \\
\hline \multirow[t]{8}{*}{ Host } & Thrashing & $\begin{array}{l}\text { Raising and quickly shaking the } \\
\text { head. }\end{array}$ & Count \\
\hline & Escaping & Moving by quickly crawling & Binary \\
\hline & & away from the approaching wasp & \\
\hline & & by more than three times its own & \\
\hline & & body length on the plant & \\
\hline & Dropping & Falling off the plant either to the & Binary \\
\hline & & ground or by hanging on a silken & \\
\hline & & thread. & \\
\hline \multirow[t]{5}{*}{ Wasp } & Stinging & Inserting the ovipositor inside the & Binary* \\
\hline & & host body. & \\
\hline & Host-handling time & The interval between first contact & Continuous \\
\hline & & with the host and completion of & \\
\hline & & ovipositor stinging. & \\
\hline
\end{tabular}

* The ovipositor stinging by M. pulchricornis was defined as being successful when the insertion

3 lasted more than one second and a characteristic wing-flapping occurred when withdrawing the 
4 ovipositor from the host (Zhang, Li \& Meng, 2014). For $M$ mediator, a bout of stinging always 5 results in an egg deposition (Wang et al., 1984).

6 
Figure 1

Distribution of body weight for Mythimna separata larvae with or without escaping in response to Microplitis mediator (A) and Meteorus pulchricornis (B).
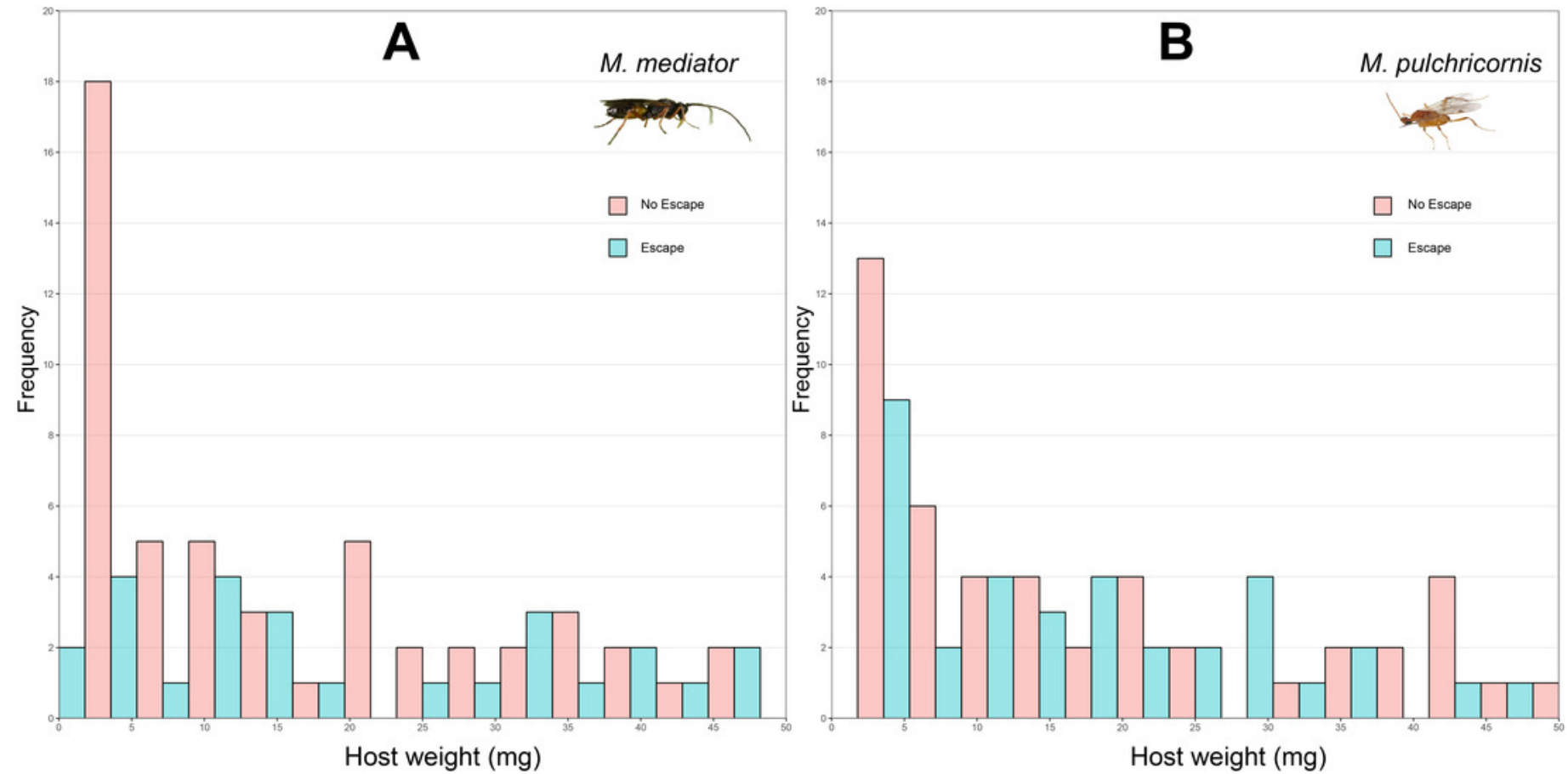
Figure 2

Distribution of body weight for Mythimna separata larvae with or without dropping in response to Microplitis mediator (A) and Meteorus pulchricornis (B).
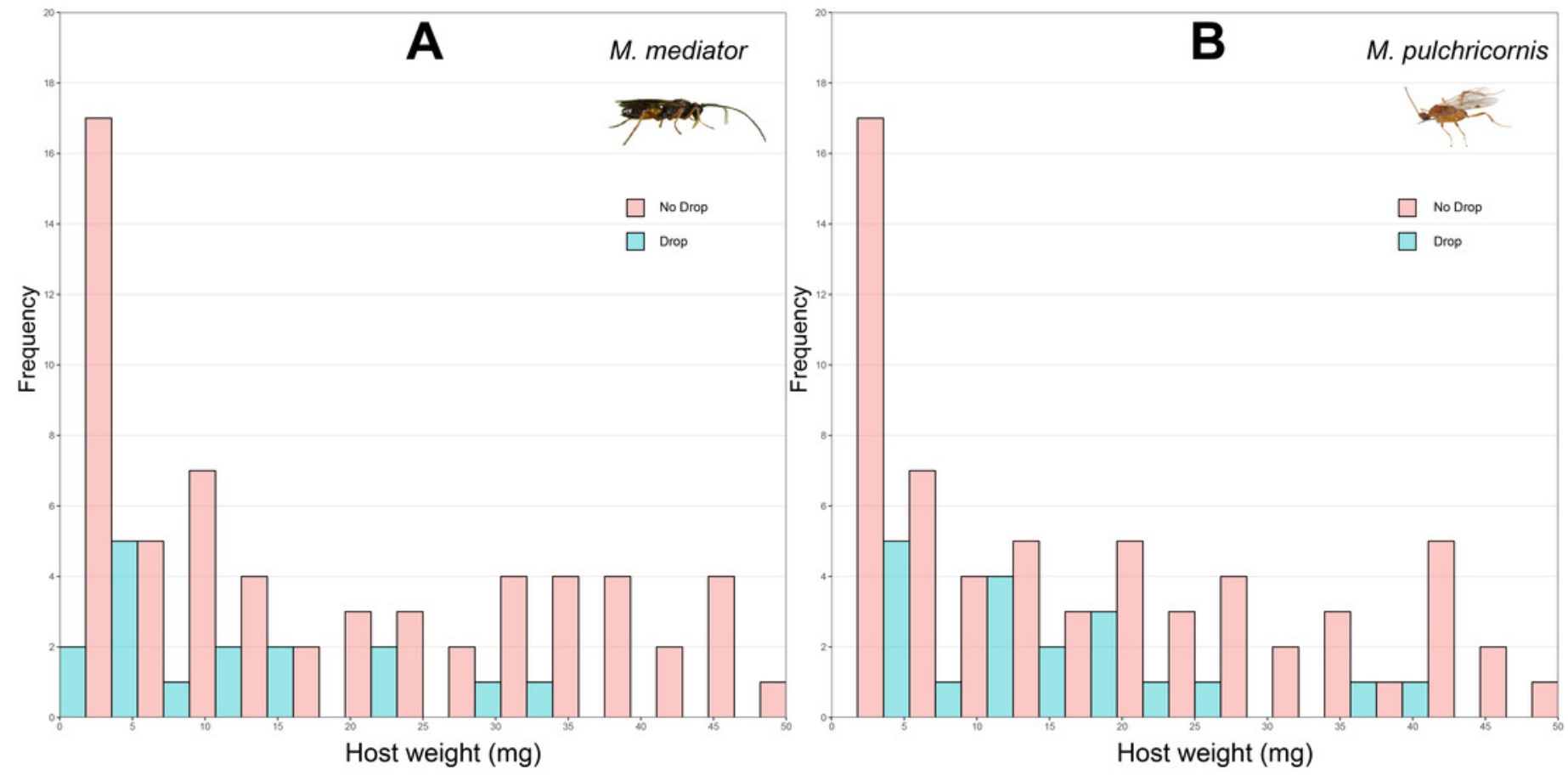
Figure 3

Intensity of thrashing of Mythimna separata larvae in response to Microplitis mediator and Meteorus pulchricornis.

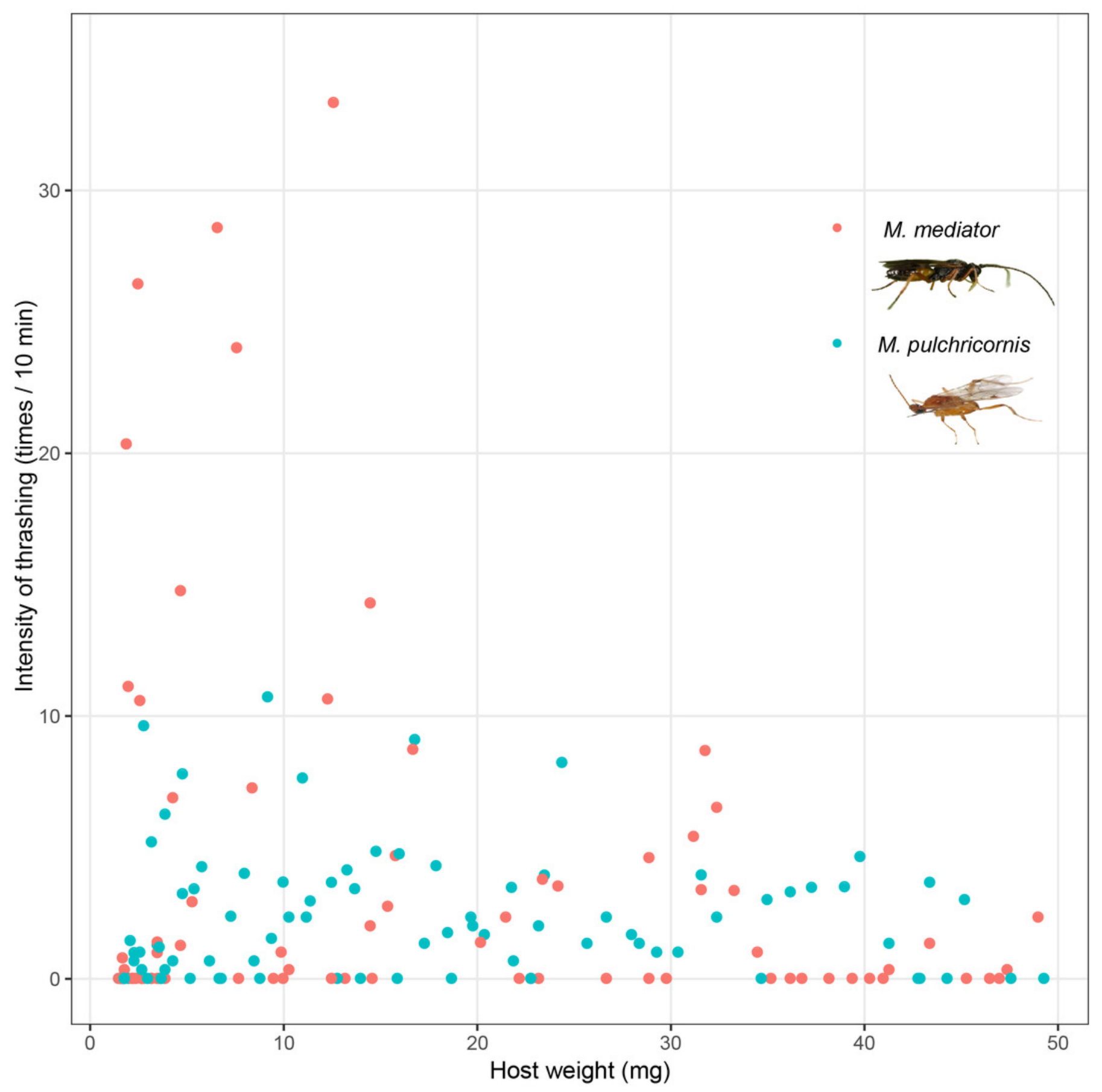


Figure 4

Probability of stinging as a function of both Mythimna separata larval body weight and thrashing frequency for Microplitis mediator (A) and Meteorus pulchricornis (B).

The grid surface is predicted probabilities from logistic regression models.

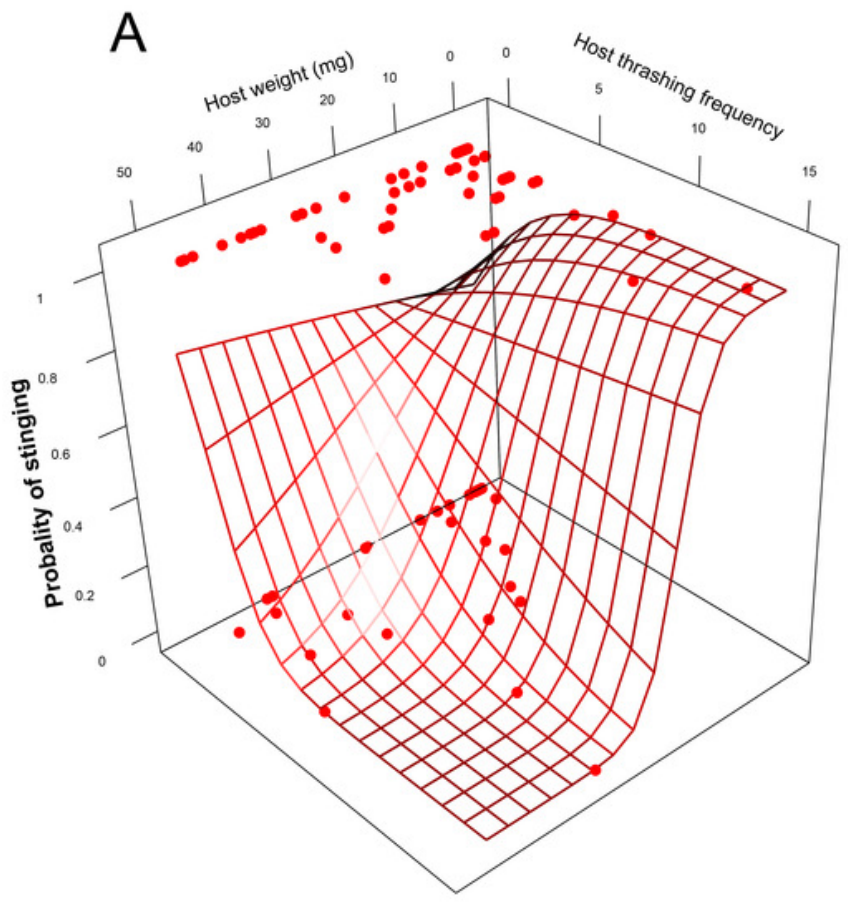

M. mediator

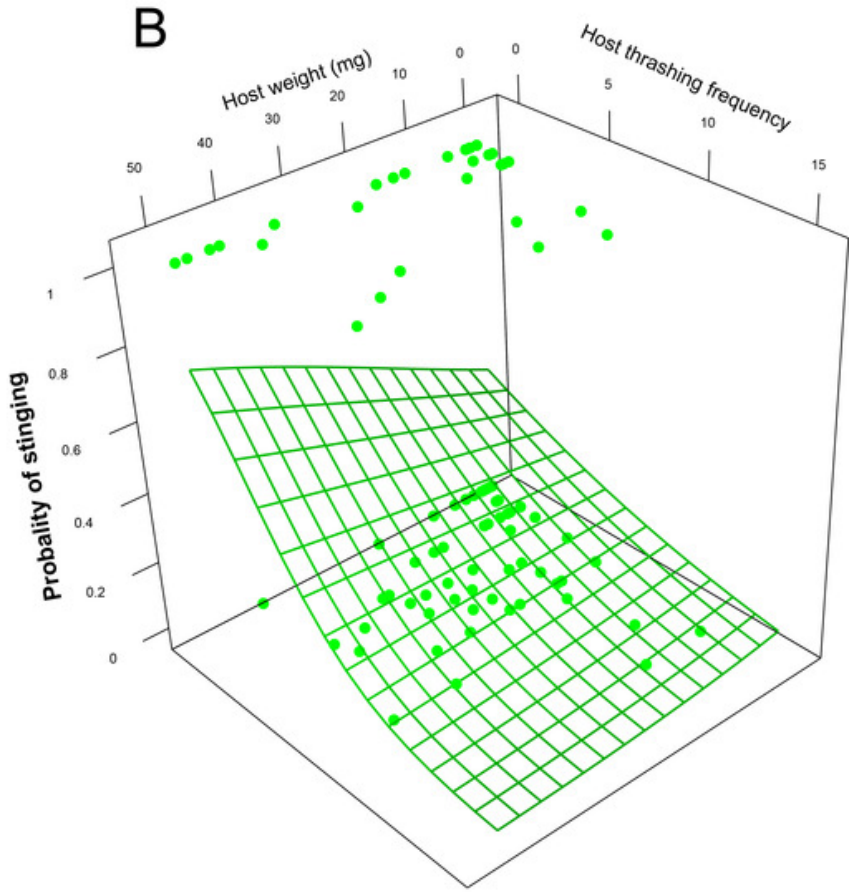

M. pulchricornis 
Figure 5

Host-handling time as a function of Mythimna separata larval body weight (A) and thrashing frequency (B) for Microplitis mediator and Meteorus pulchricornis.
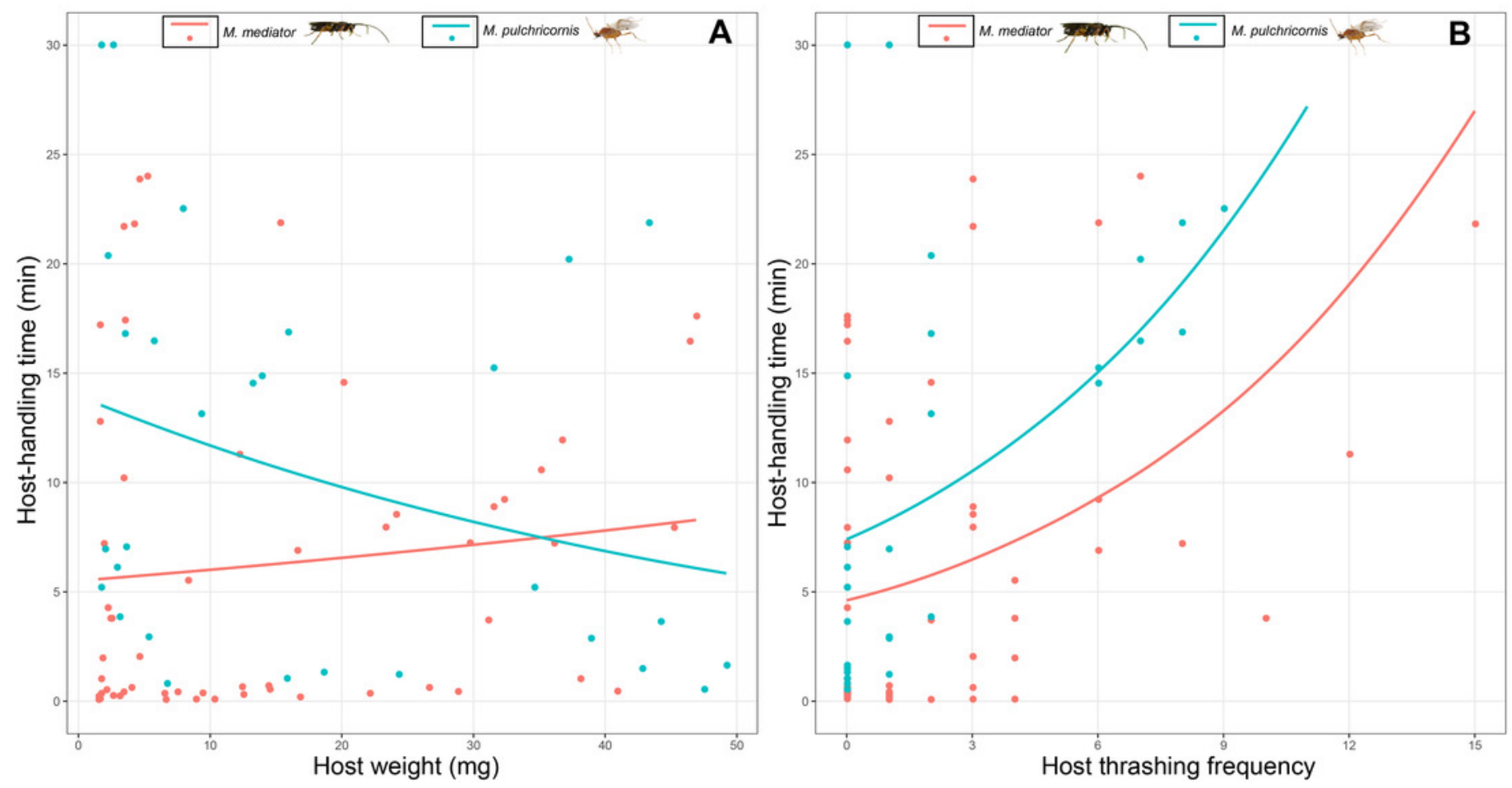